\title{
Comunicación de la predicción: comunicación de crisis meteorológica
}

https://doi.org/10.31978/639-19-010-0.747

\author{
José Ángel Núñez Mora1 (jnunezm@aemet.es) \\ Manuel Mora García² (mmoray@aemet.es) \\ Jesús Riesco Martín³ (jriescom@aemet.es) \\ ${ }^{1}$ AEMET / Delegación Territorial en la Comunidad Valenciana \\ ${ }^{2}$ AEMET / Delegación Territorial en Castilla y Léon \\ ${ }^{3}$ AEMET / Delegación Territorial en Andalucía / Centro Meteorológico de Málaga
}

\begin{abstract}
RESUMEN
Existen dos apartados importantes a tener en cuenta en los que el concepto de riesgo para la población o sus bienes es fundamental. Por un lado la comunicación clara de la predicción de manera sistemática al gran público desde los Centros de Predicción y Vigilancia, de manera fluida y actualizada a través de distintos procedimientos, manifestando de modo claro la predicción y sus incertidumbres con un enfoque orientado a impactos. Y por otro lado, y muy especialmente, establecer mecanismos nuevos para avisar de situaciones de alta probabilidad de fenómenos con alto impacto o el agravamiento de dichos fenómenos en situaciones de alto riesgo.

En la sociedad actual, acostumbrada a la inmediatez de la información que proporcionan las redes sociales, la comunicación interna de AEMET se puede completar con información cualificada y de calidad a través de las redes sociales. Se deben explorar vías concretas para conseguir una comunicación sencilla, inmediata y actualizada de la predicción y los avisos meteorológicos, sobre todo en episodios que pueden poner en peligro bienes materiales y vidas humanas. Concretamente los episodios de nevadas copiosas y de tormentas fuertes y precipitaciones intensas podrían ser abordados de una manera especial, para tratar de poner a salvo a la población con un cierto margen de maniobra ante situaciones de desencadenamiento rápido y de potencial adversidad manifiesta.
\end{abstract}

PALABRAS CLAVE: comunicación; predicción meteorológica; canales de comunicación; redes de información; protección civil; medios de comunicación; opinión pública.

\section{INTRODUCCIÓN TEÓRICA: NECESIDAD DE ADAPTACIÓN AL NUEVO ESCENARIO SOCIAL, MEDIÁTICO, TECNOLÓGICO Y CIENTÍFICO}

Es evidente que el escenario social y mediático actual difiere notablemente del escenario de hace solo unas décadas, cuando se creó gran parte de la estructura de la Agencia Estatal de Meteorología. En lo que se refiere a la comunicación, a lo largo de este siglo se han ido desarrollando nuevas formas, especialmente las referidas a la comunicación de situaciones de crisis, situaciones muy abundantes en el campo de la meteorología, sobre todo en el ámbito de las comunidades del Mediterráneo.

En este punto, hay que destacar que en los últimos años se ha puesto fin al escenario de comunicación unidireccional, en el que existía un único actor en el mundo de la meteorología, el organismo oficial, AEMET, INM o cualquiera de sus denominaciones anteriores, y se ha pasado a una realidad alternativa a la institucional, 
en la que el número de actores se ha multiplicado, con multitud de redes de observación meteorológica, algunas de organismos de la administración (redes SAIH de confederaciones hidrográficas, redes de observación de comunidades autónomas, redes desplegadas por servicios meteorológicos autonómicos, etcétera), y otras estaciones meteorológicas privadas cuyos datos se vuelcan en plataformas abiertas disponibles al público en general.

Además de los datos de observación, cada vez hay más y más detallada información en la red de modelos numéricos y de herramientas de teledetección, cuyo acceso anteriormente estaba restringido a los servicios meteorológicos oficiales. Estos datos se comentan ampliamente en foros especializados de meteorología y en redes sociales.

La introducción de nuevos actores en el mundo de la meteorología, cada uno con su rol y responsabilidad, implica que progresivamente se ha ido perdiendo el control del discurso por el organismo oficial, que antes era único y operaba en única dirección (desde el organismo oficial hacia el medio de comunicación), y ahora se ha convertido en multidireccional, con muchos actores interactuando tanto en situaciones ordinarias como de crisis meteorológica, y no pocas veces la información de lo que está ocurriendo llega al organismo oficial a través de otras redes de observación meteorológica o de información procedente de testigos directos de lo que está ocurriendo a través de las redes sociales.

Este nuevo panorama implica que, cuando están sucediendo fenómenos meteorológicos adversos, que es lo que llamaríamos situaciones de crisis meteorológica, puede surgir un relato alternativo al del organismo oficial, y en caso de demora en la presencia de portavoces de este explicando lo que está ocurriendo, puede poner a la organización en una situación incómoda, ya que la tardanza en empezar a contar lo que está sucediendo, implica la pérdida de la iniciativa ante una situación que ya ha comenzado a ser comentada por terceros, acertadamente o no.

La presencia en tiempo real de portavoces cualificados del organismo oficial está sometida a riesgos. Un mensaje confuso o dubitativo por parte de un portavoz oficial, por ejemplo, puede contribuir a agravar la crisis, por lo que la presencia de personas muy expertas al frente de la comunicación en tiempo real se hace necesaria, y no solo es necesaria la experiencia comunicativa, sino la experiencia en los campos de la meteorología y la climatología.

Otro factor que destaca en la comunicación contemporánea es que poco a poco se va prescindiendo de intermediarios y cada vez prima más la comunicación directa a través de las redes sociales. Esto no significa que para el organismo oficial de meteorología el periodista sea prescindible; el organismo oficial no es un medio de comunicación, sino un servicio público de la administración, y como tal debe de actuar. La experiencia indica que los mensajes que el servicio oficial va lanzando a través de las redes sociales, no solo son escuchados por ciudadanos, sino también por autoridades, equipos de emergencias y periodistas. Estos, con la información que reciben del organismo meteorológico y con el resto de información procedente de otros organismos implicados (protecciones civiles, confederaciones hidrográficas, equipos de salvamento, bomberos, etcétera), pueden construir un relato de los hechos coherente y presentarlo en sus medios tradicionales (radio, televisión, prensa) o digitales, con una narrativa completa de los fenómenos meteorológicos que se han generado y sus impactos.

Progresivamente las nuevas generaciones van cambiando sus preferencias para informarse, y van alternando la información que reciben a través de los medios tradicionales, con la que reciben a través de medios «en línea», e incluso en el caso de los internautas más jóvenes, la preferencia de recibir información meteorológica a través de medios digitales ya ha superado con creces a la que reciben por televisión, que sigue siendo el canal preferido como fuente de información por la mayoría de la población. 
En cuanto a la forma en la que se emiten los mensajes en los casos de crisis meteorológica, recientes estudios han encontrado una mayor efectividad de los mensajes basados en la narrativa que de los mensajes lanzados a través de boletines ordinarios. La construcción de un relato para transmitir un mensaje en el que el usuario final se vea directamente aludido, con referencias cercanas que para él sean identificables (el nombre de su pueblo, de un accidente geográfico cercano, etcétera), contribuye a que el mensaje llegue a una población más amplia y a una mayor asunción del riesgo meteorológico.

Los trágicos efectos del tifón Haiyan en la ciudad de Tacloban (Filipinas), en noviembre de 2013, y la actitud de la población local ante los avisos que recibieron del organismo oficial, fueron estudiados por LEJANO, CAsas, Montes y Lengwa (2018). Ese tifón está considerado como el más intenso de los registrados que han tocado tierra y provocó más de seis mil víctimas. Los autores del estudio — citado en la bibliografíallegaron a la conclusión de que la catástrofe humanitaria que provocó el tifón a su paso por Filipinas se debió en parte a la incapacidad de los boletines rutinarios para comunicar de forma eficaz la naturaleza sin precedentes de la marea de tempestad que se preveía.

A raíz de ese estudio, los autores construyeron un modelo relacional de comunicación de riesgos (tabla 1), que sugiere que los mensajes narrativos que simulan la comunicación directa, cara a cara, pueden ser más eficaces para tomar medidas de prevención o incluso para decidir realizar la evacuación voluntaria de una zona cuando las autoridades así lo indican, que los boletines ordinarios.

Con este modelo, frente a los boletines ordinarios, se pone de manifiesto la mayor efectividad de los mensajes creados ad hoc que se emiten en una situación de crisis, en los cuales prima el lenguaje cotidiano (frente al lenguaje técnico de los boletines ordinarios), la estructura del mensaje en segunda persona, dirigiéndose directamente al ciudadano (frente a las oraciones impersonales de los boletines rutinarios), la viveza descriptiva (frente a la precisión técnica y rigidez del mensaje de los boletines ordinarios) y la contextualización local del mensaje, con referencias reconocibles por él.

\section{Comparación entre mensajes de tipo NARRATIVO y TÉCNICO}

\begin{tabular}{|c|c|c|}
\hline Lenguaje cotidiano & $\Longleftrightarrow$ & Lenguaje técnico \\
\hline Segunda persona & $\Longleftrightarrow$ & Impersonal \\
\hline Viveza descriptiva & $\Longleftrightarrow$ & Precisión en la descripción \\
\hline Personalizado & $\Longleftrightarrow$ & Impersonal \\
\hline Contextualización local & $\Longleftrightarrow$ & Universal \\
\hline
\end{tabular}

Tabla 1. Comparación entre mensajes de tipo narrativo y técnico.

Adaptado de Lejano, R. P., Casas, E. V, Montes, R. B. y Lengwa, L. P. (2018).

Weather, Climate, and Narrative: A Relational Model for Democratizing Risk Communication.

Weather, Climate, and Society, pág. 583.

Un ejemplo de cómo un servicio meteorológico oficial adopta este tipo de mensajes con una estructura narrativa, lo encontramos en los que generó el National Weather Service de Estados Unidos a través de sus redes sociales durante los primeros días del mes de septiembre de 2018 (figura 1), alertando a la población sobre los efectos catastróficos que estaba previsto que provocase el huracán Florence. Estos mensajes no rutinarios obedecían a esta tipología narrativa, con mensajes que interpelaban directamente al ciudadano, que informaban de que había que evacuar la zona, e incluso ofrecían testimonios de otros ciudadanos que se vieron afectados por situaciones similares y salvaron sus vidas gracias a haber evacuado a tiempo su hogar. 

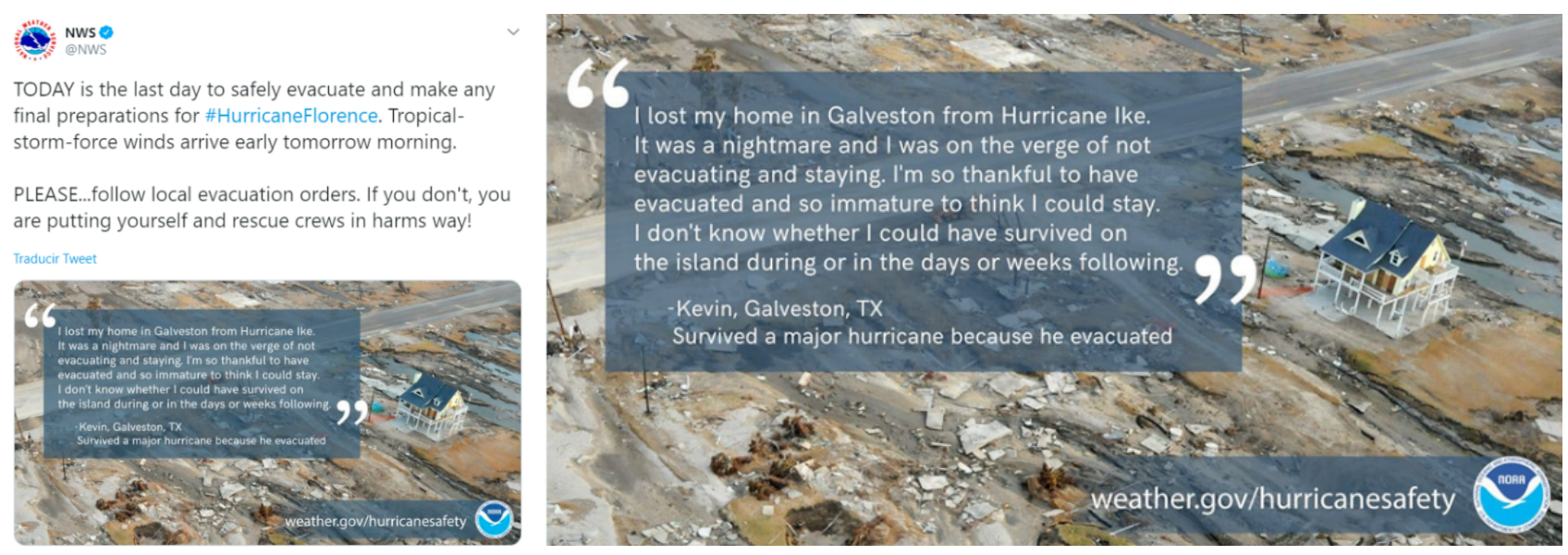

Figura 1. Mensaje de Twitter del National Weather Service de Estados Unidos del 12 de septiembre de 2018. En una parte del mensaje se podía leer: «POR FAVOR... Siga las instrucciones de evacuación locales. Si no lo haces, jte estás poniendo a ti mismo y a los equipos de rescate en peligro!

\section{UN CASO EXITOSO DE COMUNICACIÓN DE CRISIS}

Un caso exitoso en España de comunicación por parte de un organismo de la administración a través de sus redes sociales de una situación de crisis (no meteorológica), fue la comunicación que hizo el gabinete de comunicación de los Mossos d'Esquadra durante los atentados de las Ramblas de Barcelona de agosto de 2017. Para el objeto de este artículo, que está referido a la comunicación meteorológica, o a la comunicación en caso de crisis meteorológica, es poco relevante el relato detallado de cómo se fue realizando esa comunicación de los atentados de Barcelona, pero sí que es muy importante analizar por qué resultó exitosa esa comunicación, ya que la estrategia seguida sin duda puede servir de modelo a otros organismos, en concreto a la Agencia Estatal de Meteorología.

Es evidente que el éxito en aquella comunicación no fue casual y se debió a una minuciosa preparación previa. Algunas claves que nos pueden ayudar a extraer conclusiones se pueden obtener de las declaraciones posteriores que Patricia Plaja, por entonces jefa de comunicación de Mossos d'Esquadra, y Marc Homedes, jefe de comunicación de Protección Civil, hicieron a varios medios:

- «El trabajo de los últimos ocho días es producto de una reflexión desde hace dos años, en coordinación con el departamento de comunicación de Protecció Civil [...] cada vez que ocurría algo en otros países, seguíamos la información que daban los cuerpos policiales. Después empezamos a elaborar un protocolo para ver cómo lo deberíamos hacer nosotros» (BRACERO, 2017). Sin duda la reflexión y la elaboración de protocolos de comunicación en caso de crisis meteorológica es una conclusión que se puede extraer en este punto, válida para todos los organismos que tengan algo que comunicar en caso de crisis.

- Una vez que se produjo el atentado, «empezamos a dar la información que realmente teníamos. No estábamos físicamente en la Rambla, sino en el centro de coordinación del departamento de Interior. La clave es dar solo información contrastada» (BRACERO, 2017). Ofrecer al ciudadano la información verificada a medida que se va disponiendo de ella es una estrategia que proporciona tranquilidad al que la recibe. En el caso de la meteorología, se puede decir que recibir información en tiempo real de lo que está ocurriendo, simula una situación en la que se intenta dar la impresión de que el ciudadano tiene al meteorólogo a su lado.

- «Todo lo que no informes ocupará rumores en las redes, es una de las premisas bajo las cuales se ha estado trabajando y donde ha hecho falta mucha pedagogía, sobre todo para que los mandos policiales 
confiaran en esta nueva manera de comunicar» (LiÑÁN, 2017). Este punto es importante, ya que la autoridad meteorológica del Estado recae en AEMET, y si el servicio oficial, en caso de crisis meteorológica, no sale en el momento oportuno a dar información, otros sin la responsabilidad de hacerlo lo harán, o, en el peor de los casos, los rumores y las noticias falsas ocuparan el espacio que ha dejado el organismo oficial.

- «Nada más conocer lo ocurrido, nuestro objetivo fue generar confianza en la ciudadanía, dar la idea de que la situación estaba controlada y evitar que se difundieran bulos que crearan más caos» (CID, 2017). Generar confianza y dar la idea de que la situación está controlada, son claros ejemplos de servicio público por parte de un organismo de la administración, como lo es AEMET, en cuyos Estatutos se incluye de forma explícita esa vocación y se dice que las políticas de AEMET deben contribuir a «la seguridad de personas y bienes».

- Finalmente, hay que tener muy presente que el organismo oficial que comunica, en este caso AEMET, no es un medio de comunicación tradicional, sino un servicio público. Así lo dijo Patricia Plaja: «no somos un medio ni queremos serlo, sabemos que damos información de servicio público» (CID, 2017). Por tanto, el rigor, la sobriedad en el mensaje, sin adjetivos innecesarios ante una situación que puede ser grave, sin imágenes innecesarias que no aporten información, sin comentarios inapropiados, pero con un lenguaje claro y perfectamente comprensible por todos, serían principios que deberían regir en toda comunicación en una situación de crisis meteorológica.

En definitiva, y como se verá en el apartado de conclusiones, un sólido y bien formado equipo de comunicación meteorológica y climatológica, con unos protocolos claros de actuación, sin duda contribuirán a una mayor seguridad de los ciudadanos en caso de crisis meteorológica.

\section{CASO PRÁCTICO DE COMUNICACIÓN DE CRISIS METEOROLÓGICA}

Se podrían poner innumerables ejemplos de comunicación meteorológica desde los servicios centrales de AEMET o desde una de sus delegaciones territoriales, pero por la cercanía a la celebración del Sexto Simposio Nacional de Predicción, se ha elegido una situación de lluvias muy fuertes o torrenciales en la comarca de la MarinaAlta, en el litoral norte de Alicante, y la forma como se comunicó este evento meteorológico a través de la cuenta de Twitter de la Delegación de AEMET en la Comunidad Valenciana.

El día 18 de agosto de 2018 (sábado) estaba prevista una situación meteorológica de convección mediterránea por inestabilidad termodinámica en gran parte del litoral de Valencia y de Alicante. En el boletín de avisos de ese día, el predictor incluyó el siguiente comentario «mucha incertidumbre en este aviso y dos escenarios: puede no formarse ninguna lluvia, pero en el caso de que lo haga serán muy probablemente fuertes».

En esas situaciones meteorológicas la incertidumbre es altísima, pero cualquiera de los cientos de miles de ciudadanos que estuviesen ese día de agosto en algunas de las playas de Valencia y Alicante (a veces incluso con ramblas ocupadas por vehículos que actúan como aparcamiento improvisado de coches), legítimamente podrían preguntarse: ¿no es posible precisar más?

Ese día, una vez emitido el aviso, desde el Twitter de AEMET en la Comunidad Valenciana se detallaba con algo más de extensión en qué consistían esas incertidumbres en la predicción (figura 2). En la cadena de seis tweets se decía: «una de las características de las tormentas con apoyo de aire marítimo de final de verano es la elevada incertidumbre; no hay término medio, en muchas ocasiones, aunque la atmósfera esté inestable, si no se presenta el mecanismo de disparo adecuado, la lluvia es 0 . Pero si hay un mecanismo de disparo capaz de vencer la inhibición convectiva que casi siempre está presente en estas fechas en capas bajas, se pasa al otro extremo. Es decir, con situaciones atmosféricas aparentemente parecidas, o no llueve o lo hace de forma torrencial. Por eso, y más que en ninguna otra situación meteorológica, cuando está prevista la formación de 

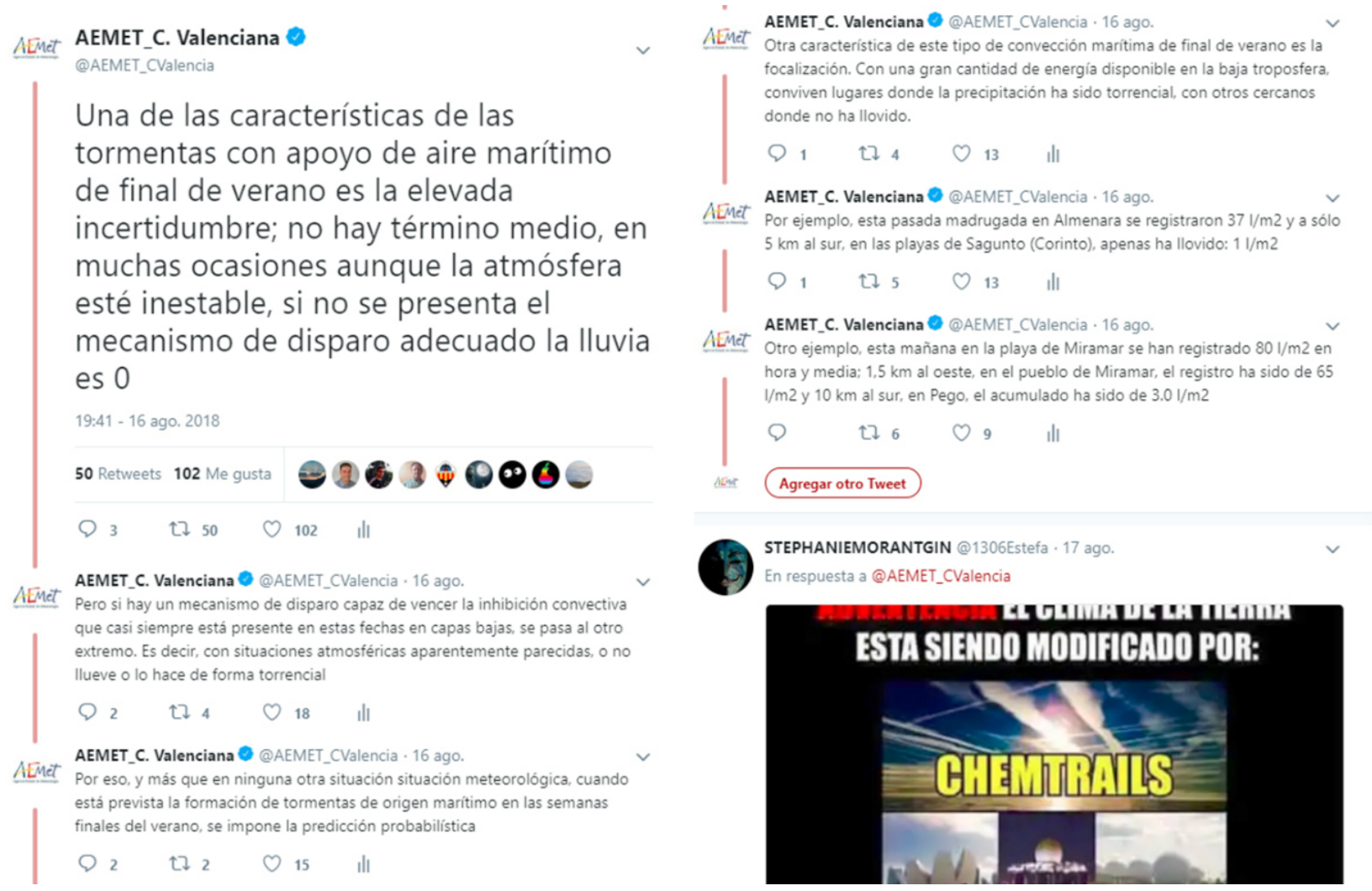

Figura 2. Comentarios del Twitter de la Comunidad Valenciana sobre las incertidumbres que plantea la convección marítima mediterránea veraniega.

tormentas de origen marítimo en las semanas finales del verano, se impone la predicción probabilística. Otra característica de este tipo de convección marítima de final de verano es la focalización. Con una gran cantidad de energía disponible en la baja troposfera, conviven lugares donde la precipitación ha sido torrencial, con otros cercanos donde no ha llovido». Es decir, no solo se explicaba el aviso, sino que se decía que, a pesar de que estuviese en aviso por tormentas el litoral de dos provincias, no significaba que la precipitación fuese a ser generalizada en esas zonas, sino que el aviso señalaba zonas de riesgo a vigilar, y las tormentas, de formarse, serían intensas pero locales.

Con esta situación es conveniente que una voz cualificada del organismo oficial esté preparada para ir relatando lo que está ocurriendo. Actualmente ya existen protocolos de comunicación directa entre el predictor operativo y las protecciones civiles o entre el predictor operativo y los centros de control, para ir transmitiendo lo que está ocurriendo o, en su caso, para informar de las modificaciones de los avisos meteorológicos, TAF o cualquier otra información que resulte relevante, pero no existe un canal de información directo entre el predictor y el ciudadano. Hay que tener en cuenta que cuando está presente la convección, la situación meteorológica evoluciona muy rápido, y a veces la información transmitida por el cauce oficial puede llegar demasiado tarde al usuario final.

En el caso que se está exponiendo, comenzó a informarse de lo que estaba sucediendo a partir del momento en el que se disparó la convección en el litoral norte de Alicante y cuando estuvo verificado que esas precipitaciones estaban teniendo intensidad muy fuerte. En un tweet emitido a las 13:01 horas (figura 3) se informaba de que «está lloviendo con intensidad muy fuerte en la zona de la Marina Alta en las proximidades de Jávea/Xàbia. Ya se han acumulado 76,2 1/ $\mathrm{m}^{2}$, de los cuales 56,4 en una hora.» A continuación, en otro tweet, se acompañaban imágenes del radar de Murcia de las últimas tres horas y se explicaba que las lluvias que se estaban registrando en Jávea se ajustaban al patrón esperado de lluvias de «tipo cálido», con pocos rayos, reflectividades radar no muy elevadas, pero muy eficientes y que permanecían ancladas tocando tierra en una pequeña zona próxima al cabo de San Antonio. 


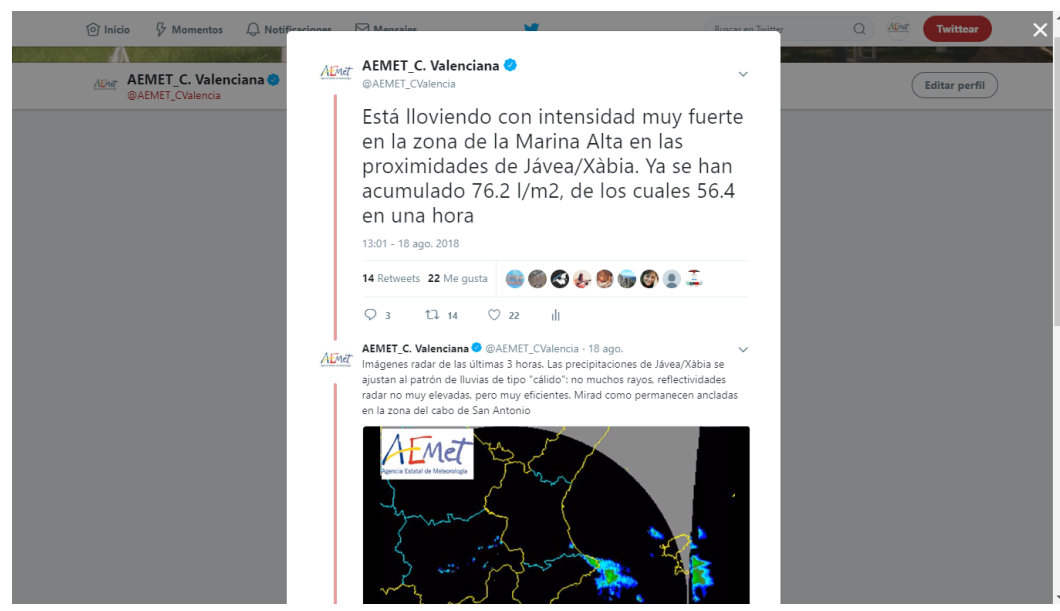

Figura 3.

Tweet de las 13:01 horas del 18 de agosto de 2018 en el que se informa que está lloviendo con intensidad muy fuerte en la zona de Jávea.

A las 14:28 horas, cuando cesó la precipitación, se comenzó a informar del balance final de lluvias, con el total de precipitación acumulada $\left(106,41 / \mathrm{m}^{2}\right)$ y un hietograma de cómo fueron evolucionando las precipitaciones (figura 4).
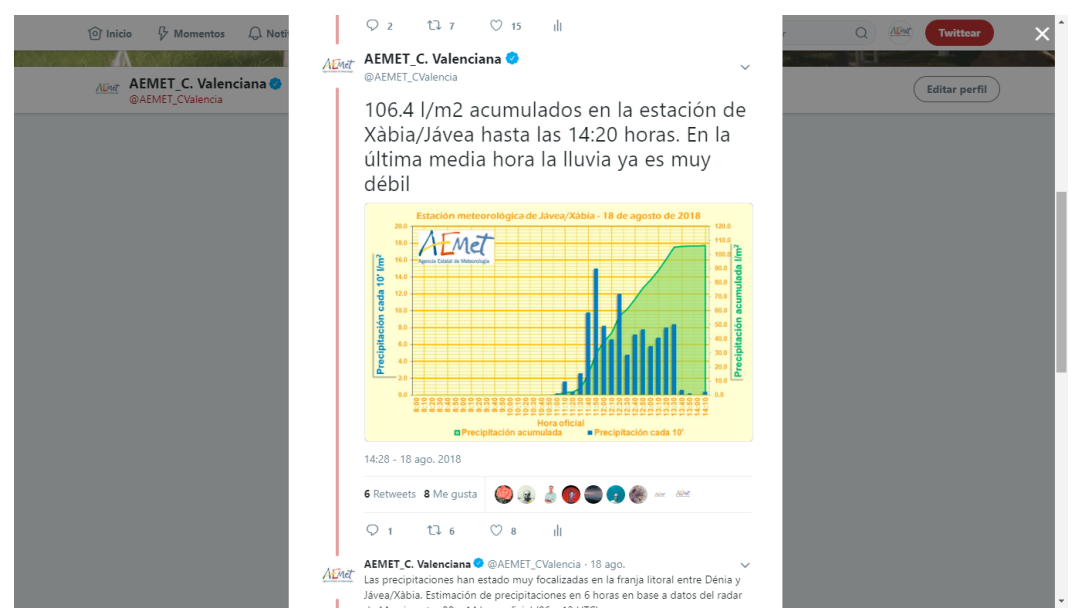

Figura 4.

Tweet de las 14:28 horas del 18 de agosto de 2018 en el que se informa que está cesando la precipitación en la zona de Jávea y se acompaña del dato de precipitación acumulada y un hietograma de la estación meteorológica de Jávea.

En estas ocasiones, y una vez que las precipitaciones han cesado, es muy útil ofrecer imágenes de precipitación acumulada estimada en base a datos radar, y aunque en muchas ocasiones el valor numérico de la estimación difiere de los registros reales, sí que suelen acotar muy bien la zona afectada por las precipitaciones intensas. En este caso, a través de Twitter se adjuntó una estimación de precipitación en 6 horas del radar de Murcia en la que quedaban bien delimitadas las zonas afectadas por las intensas precipitaciones del $18 \mathrm{de}$ agosto de 2018 (figura 5).
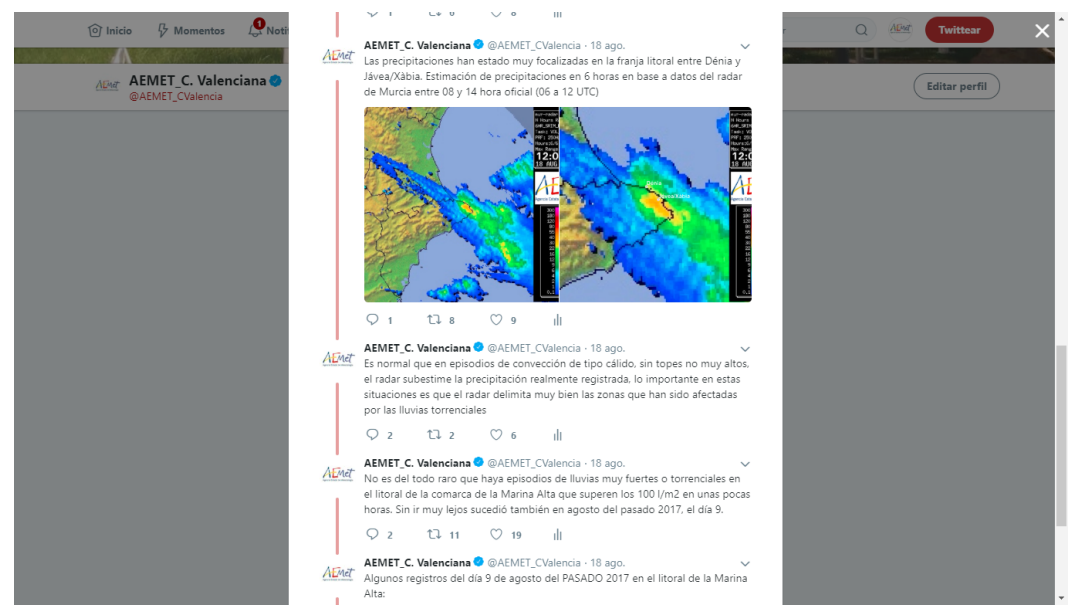

Figura 5.

Tweet con la imagen de la estimación de precipitación del radar de Murcia y comentarios de la imagen. 
Por último, y una vez finalizada la situación meteorológica, se pueden hacer valoraciones climatológicas sobre la rareza o no del evento registrado y su contextualización con situaciones meteorológicas recientes. En este caso, en varios tweets se comentó que «no es del todo raro que haya episodios de lluvias muy fuertes o torrenciales en el litoral de la comarca de la Marina Alta que superen los $1001 / \mathrm{m}^{2}$ en unas pocas horas. Sin ir muy lejos, sucedió también en agosto del pasado 2017, el día 9.» Además se ofrecían datos de la precipitación acumulada en el episodio citado del año anterior.

\section{CONCLUSIONES}

La planificación y la creación de protocolos de actuación ante un escenario de crisis son necesidades que deberían abordar todos los organismos, especialmente en un ámbito tan sensible como la meteorología, donde los fenómenos adversos son muy frecuentes, a veces generando víctimas y grandes daños en infraestructuras.

En un Estado con muchas competencias transferidas a las comunidades autónomas, especialmente la protección civil, se ha demostrado eficaz realizar la comunicación meteorológica desde las mismas delegaciones territoriales de AEMET cuando el fenómeno que se está desarrollando incumbe solo al territorio de una comunidad, por lo que no solo es necesario la creación de protocolos y estrategias en el ámbito nacional, sino también en el ámbito autonómico, y consensuar estos protocolos de comunicación en caso de crisis meteorológica con la protección civil nacional y también con las protecciones civiles autonómicas.

De esta forma, se deberían abrir vías concretas para conseguir una comunicación sencilla, inmediata y actualizada de la predicción y los avisos meteorológicos, sobre todo en episodios que pueden poner en peligro bienes materiales y vidas humanas.

Para dar continuidad a la comunicación meteorológica y climatológica, sería necesario la creación de equipos estables de comunicación regionales, con personal dedicado a estas tareas (que se pueden compaginar con otras funciones meteorológicas y climatológicas), y con garantía de continuidad de la comunicación sobre todo en casos de crisis meteorológica. Para ello, puede resultar muy importante la ampliación de los actores implicados en la comunicación de crisis meteorológica a todos los departamentos, áreas, servicios y secciones de AEMET, especialmente a personal del Sistema Nacional de Predicción y del Área de Climatología, cuyos conocimientos son fundamentales para la elaboración de un mensaje adecuado antes de su emisión al gran público.

\section{REFERENCIAS}

Bracero, F., 2017. El ejemplo de los Mossos: así se comunica un atentado al mundo. La Vanguardia, 26 de agosto.

Casals Carro, A., 2015. Estudio de Reputación de AEMET. AEMET, Madrid.

CID, G., 2017. Así se actúa en un atentado: este es el equipo humano tras @ mossos y @emergenciescat. El Confidencial, 24 de agosto.

Fischetti, M., 12 de noviembre de 2013. Was Typhoon Haiyan a Record Storm? Scientific American. https://blogs.scientificamerican.com/observations/was-typhoon-haiyan-a-record-storm/.

Lejano, R. P., Casas, E. V., Montes, R. B. y Lengwa, L. P., 2018. Weather, Climate, and Narrative: A Relational Model for Democratizing Risk Communication. Weather, Climate, and Society, 10 (3), 579-594. https://doi.org/10.1175/WCAS-D-17-0050.1.

LiÑÁn, G., 2017. Detrás del Twitter de los Mossos: Dos años de trabajo. El Nacional.cat, 23 de agosto.

Losada Díaz, J., 2018. (No) Crisis. Editorial UOC, Barcelona. 